\title{
Quercetin 3-Glucoside-7-Rhamnoside from Hippophae rhamnosides L. Fruits Attenuate Allergy in Ovalbumin- Induced Allergic Mouse
}

\author{
Hwa-Jung Choi* \\ Kwangju Women's University, South Korea \\ *Corresponding author: Hwa-Jung Choi, Department of Beauty Science, Kwangju Women's University, 165 Sanjeong- \\ dong, Gwangsan-gu, Gwangju 506-713, South Korea
}

\begin{abstract}
ARTICLE INFO
Received: 幽 September 02, 2019

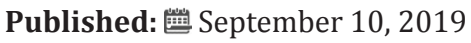

Citation: Hwa-Jung Choi. Quercetin 3-Glucoside-7-Rhamnoside from Hippophae rhamnosides L. Fruits Attenuate Allergy in Ovalbumin-Induced Allergic Mouse. Biomed J Sci \& Tech Res 21(2)2019. BJSTR. MS.ID.003574.
\end{abstract}

Keywords: Q3G7R; Allergic model; Inflammation; Anti-allergy effect

\begin{abstract}
Various studies have shown that flavonoids have several pharmacological activities. In the present study, the anti-allergic activities of 3-O-glucoside-7- $O$-rhamnoside (Q3G7R) from Hippophae rhamnoides L. fruits was investigated in ovalbumin (OVA)induced mouse allergic model. Allergy was induced by intraperitoneal injection of ovalbumin into balb/c mice. After 4 weeks, IgE level by mouse IgE ELISA Kit, histamine level by fluorometric method and tryptase level by Immuno CAP Tryptase reagents in serum, and then the levels of $\mathrm{T}_{h} 2$ cells-derived cytokines interleukin (IL)-4 and IL-13 by ELISA kit in spleencyte were observed. As the results, Q3G7R showed significant a reduction of OVA-specific IgE levels in serum, decrease of histamine and tryptase level in serum, and then the decrease of the levels of $\mathrm{T}_{\mathrm{h}} 2$ cells-derived cytokines interleukin IL-4 and IL-13 in spleencyte. In histological analysis for lung, Q3G7R excellently reduced eosinophil infiltration with inhibition of characteristic lesions and inflammation including ovalbumin (OVA)-induced necrosis, numbers of inflammatory cells and pulmonary edema. Therfoure, Q3G7R showed anti-allergy effect in mouse allergic model and may be a potential agent for the treatment of allergic disease.
\end{abstract}

\section{Introduction}

Allergy are a serious health topic today in many countries [1]. Allergy are very patient peculiarity and include various allergies and skin symptoms [2]. Allergy have come to epidemic proportions in international world and incidence of allergy is continuing to growth in relation with the present lifestyles [3]. Therefore, it is urgent to understand the pathophysiology and care strategies of the various allergic diseases influencing the population of the world.

Pharmacotherapy of allergy includes anti-allergic drugs, bronchodilators, and corticosteroids [4,5]. These products are clinically limited because of their side effects such as hyperlipidemia, susceptibility to pathogens and hyperglycemia [6]. Ayurvedic medicines include several plants possessing medicinal efficacy in its formulations for the care of allergic diseases [7]. Thus, it can be undoubted that the therapy using herbal medicines could be a potential alternative in the pharmacotherapy of allergic diseases.
Hippophae rhamnoides L. (HR) is a hardy, deciduous shrub belonging to family Elaeagnaceae [8]. It grows in Central Asia and Europe [9]. This plant has lately gained world's attention because of its various potential. A HR fruits, seed and other parts is primarily valued for its very rich physiological compounds [10]. Fruit of HR is one of the few exclusions among carotenoid-rich plants that contain abundant lipids [11].

For centuries, the people of Asia have used HR as a candidate of alternative medicine to prevent various diseases. The HR fruits were used as a fountainhead of herbal medicines and skin care in the world including Europe and Asia [9]. A wide spectrum of pharmacological effects of HR have been recently published, including antioxidant efficacy, immunomodulatory effect, and hepatoprotective function [10-21]. Modern various studies also have exhibited that flavonoids are the active components in HR [22,23]. Flavonoids from HR have 
anti-tumor activity and antioxidant activity and have been widely used in the study of natural medicine as well as in practical clinic [24-26].

In this study, we identified 3-O-glucoside-7-O-rhamnoside (Q3G7R) from H. rhamnoides L. fruits. The IgE level, histamine and tryptase level in serum of balb/c mice induced allergy by intraperitoneal injection of ovalbumin (OVA) were observed. $\mathrm{T}_{\mathrm{h}} 2$ cells-derived cytokines interleukin (IL)-4 and IL-13 in spleencyte were observed. Furthermore, the effect of Q3G7R on changes in characteristic lesions, inflammation and eosinophils was examined in the mice.

\section{Materials and Methods}

\section{Reagents and Apparatus}

Dexamethasone, ovalbumin and dimethylsulfoxide (DMSO) were purchased from Sigma (St. Louis, MO, USA). All other chemicals were of reagent grade. Trypsin-EDTA, DMEM and FBS were purchased from Gibco BRL (Grand Island, NY, USA). Interleukin (IL)-4, IL-13, Immunoglobulin E (IgE) ELISA kit (Biosource, USA), anti-CD3 (serotec., UK.), homogenizer (OMNI, Co., USA), plate shaker (Lab-line, Co., USA), flow cytometer (Molecular Devices, Co., USA), ELISA reader (Molecular Devices, Co., USA) were used. NMR spectra were recorded at $400 \mathrm{MHz}$ for ${ }^{1} \mathrm{H}-\mathrm{NMR}$ on a Varian Germini 200 spectrometer and $100 \mathrm{MHz}$ for ${ }^{13} \mathrm{C}-\mathrm{NMR}$ on a Varian VXR-30 spectrometer. Chemical shifts are given in ppm on the $\delta$ scale using tetramethylsilane (TMS) as an internal standard. Mass spectra were obtained on electrospray ionization mass spectrometry (ESI-MS, Fisons VG Quattro 400 mass spectrometer, USA). C18 functionalized silica gel 60 (0.063-0.200 mm, Merck, Darmstadt, Germany) was used for column chromatography. Pre-coated silica gel plates (Silica gel $60 \mathrm{~F}_{254}, 0.20 \mathrm{~mm}$, Merck) were used for analytical thin layer chromatography (TLC). A high-performance liquid chromatography (HPLC) (SCL-10 AVP, Shimadzu, Kyoto, Japan) was used for isolation of active principles.

\section{Extraction and Isolation}

The parched fruits of Hippophae rhamnoides L. were purchased from the herbal store in Korea. The parched fruits of $H$. rhamnoides L. (1 $\mathrm{kg})$ were extracted with EtOH (10L) for 3 days at room temperature and concentrated under vacuum. The extract (32 g) was sequentially partitioned into hexane (1.13g), ethyl acetate $(3.74 \mathrm{~g})$, and butanol $(7.32 \mathrm{~g})$ portions (Figure 1). The organic solvent fractions were concentrated to dryness by rotary evaporation at $40^{\circ} \mathrm{C}$. The concentrated ethyl acetate fraction (3.74 g) was subjected to reverse phase column chromatography (YMCGel RP-18, 70-230 mesh, 300 g) with step gradient elution using $\mathrm{MeOH} / \mathrm{H}_{2} \mathrm{O}(20: 80,40: 60,60: 40,80: 20$ and 100:0; each 500mL) to give 7 sub-fractions. For further purification, the fractions from 3 to 4 (90mg) was successively separated by semi-preparative HPLC

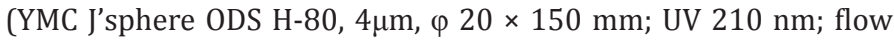
rate $1.8 \mathrm{~mL} / \mathrm{min}$ ) with elution by $\mathrm{MeOH} / \mathrm{H}_{2} \mathrm{O}$ (45:55), and gave the pure compound 1 (14 mg). For the identification of compound 1, spectroscopic analysis including ESI-MS, ${ }^{1} \mathrm{H}-\mathrm{NMR}$ and ${ }^{13} \mathrm{C}-\mathrm{NMR}$ spectral data was performed. Based on ESI-MS, ${ }^{1} \mathrm{H}$ NMR and ${ }^{13} \mathrm{C}$ NMR spectral data, the purified compound was verified Q3G7R (Figure 2) [27].

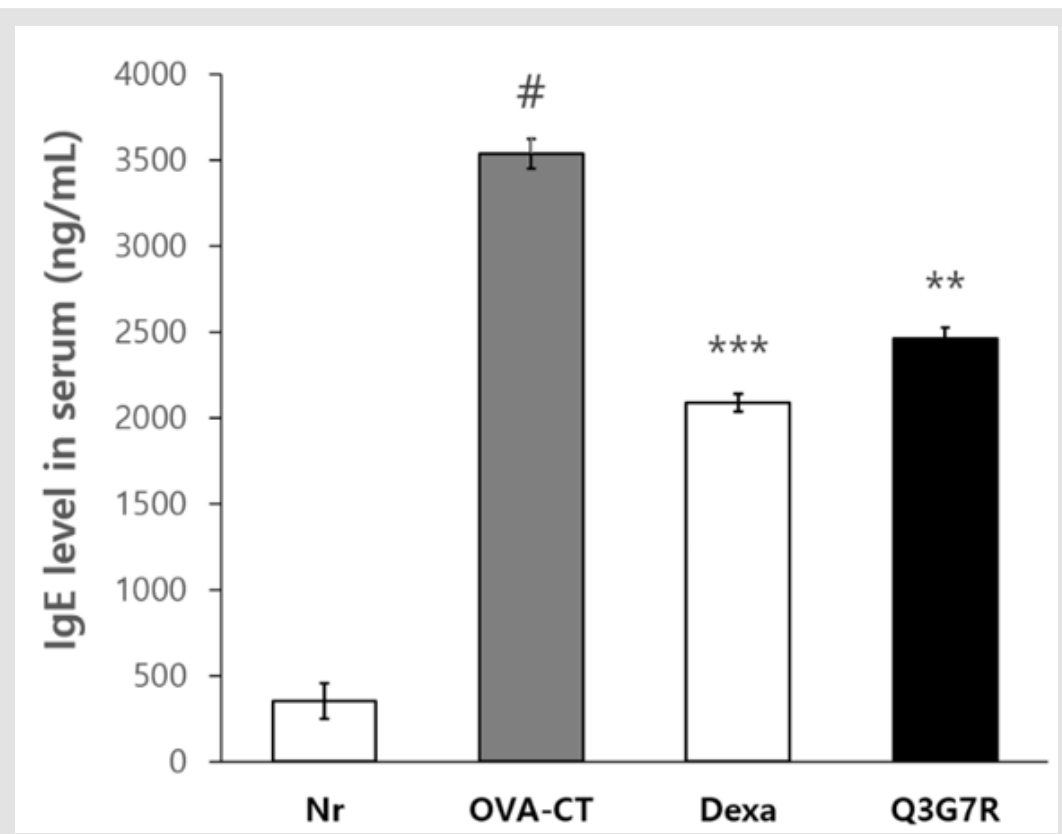

Figure 1: Effect of Q3G7R on the serum IgE levels in ovalbumin applied Balb/c. Six-week-old Balb/c male was used and ovalbumin was injected in intraperitoneally of them for $0,7,14,21$ and 28 days to Balb/c ( $=5)$. The Q3G7R containing 100 $\mathrm{mg}$ of Q3G7R/ $\mathrm{kg}$ body weight per day, dissolved in $0.4 \%$ polyethylene glycol in $0.5 \% \mathrm{EtOH}$, were applied topically, on a daily basis, for 4 weeks. IgE cytokines levels in the serum were determined by ELISA kit. Nr, normal; OVA-CT, ovalbumin control; Dexa, dexameason. Q3G7R, 3-O-glucoside-7-O-rhamnoside. \#Significantly different from normal group ( $p>0.05$ ). **Significantly different from OVA-CT groups $(p>0.01) .{ }^{* * * S i g n i f i c a n t l y ~ d i f f e r e n t ~ f r o m ~ O V A-C T ~ g r o u p s ~}(p>0.001)$. 


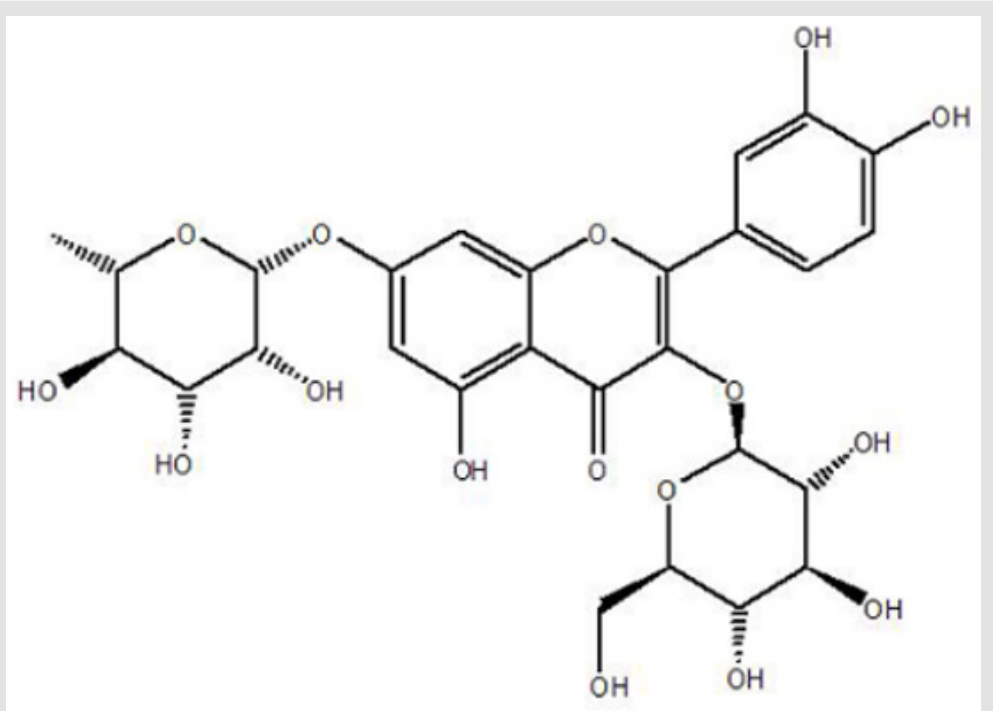

Figure 2: Structure of Q3G7R.

\section{Animal and Application}

Five-week-old male Balb/c mice were purchased from Charles River Japan (Kanagawa, Japan). Mice were housed at $21 \pm 2$ with $55 \pm 15 \%$ humidity of a 12 hrs light-dark cycle (light on 7 AM, 7 PM). All experimental protocols were approved by the Institutional Animal Care and Use Committee (IACUC) of Daejeon University, South Korea (DJUARB2013-028). All procedures were executed according to the Guide for the Care and Use of Laboratory Animals. After preliminary breeding for 1 week, the mice were divided into five groups, including a normal group ( $\mathrm{Nr} ; \mathrm{n}=5)$, ovalbumin-control group (OVA-CT; $n=5$ ), dexamethasone group (Dexa; $n=5$ ) and Q3G7R group (Q3G7R; $n=5$ ), and acclimated for 1 week before use. Balb/c male (6-week-old) was used and ovalbumin was injected in intraperitoneally of them for $0,7,14,21$ and 28 days to Balb/c. The Q3G7R containing $100 \mathrm{mg}$ of Q3G7R/kg body weight per day, dissolved in $0.4 \%$ polyethylene glycol in $0.5 \% \mathrm{EtOH}$, were applied topically, on a daily basis, for 4 weeks.

\section{Measurement of IgE Level}

To measure IgE level in serum, animals were anesthetized for euthanasia with the following reagents: isoflurane and sodium pentobarbital. Isoflurane was administered by inhalation at an overdose of $4 \%$ with oxygen as a carrier gas for 5 min in a sealed chamber at a pressure of 6 psi by using inhalation anesthesia apparatus (IWOO Scientific Corporation, Seoul, Korea) at room temperature to induced euthanasia according to the IACUC Guidelines for the Euthanasia of Korea. The blood samples were centrifuged at $4000 \mathrm{~g}$ for $10 \mathrm{~min}$, and serum was collected and stored at $-20^{\circ} \mathrm{C}$ until use.IgE levels in the serum were determined by mouse IgE ELISA Kit (LifeSpan BioScience, Inc., WA, USA). Each antibody diluted with the coating buffer was coated on the surface of microplate at $4^{\circ} \mathrm{C}$ overnight. Each well was washed three times with washing buffer and then $100 \mu \mathrm{L}$ of culture fluid or serum $(100$ fold diluted) was dispensed into the plate for $1 \mathrm{~h}$. Then the plate was washed twice, and $100 \mu \mathrm{L}$ of Avidin-HRP conjugated antibody was treated, washed, and TMB solution was treated for $30 \mathrm{~min}$ in the dark condition. After stopping the reaction with $50 \mu \mathrm{L}$ of stop solution, the absorbance at $450 \mathrm{~nm}$ was measured by using ELISA reader.

\section{Histamine and Tryptase Assay in Serum}

The heparinized blood was processed immediately and/ or kept at $4^{\circ} \mathrm{C}$ (a maximum of 24-48 hrs) after its extraction and subsequently centrifuged to separate the plasma that was processed afterwards to quantify the amount of histamine. Plasma histamine was determined using the fluorometric method following the technique modified by Siraganian [28] with an AutoAanalyzer 3 (Bran Luebbe, SEAL Analytical Inc, Mequon, WI, USA). Serum tryptase levels were determined with the B12 assay [29], using Immuno CAP Tryptase reagents and the Phadia 250 analysis device (Phadia AB, Uppsala, Sweden).

\section{Measurement of Cytokines Level}

Animals were killed by decapitation one day after measurement of IgE level, histamine and tryptase levels. To measurement of cytokines level, OVA/alum was conducted by intraperitoneal injection. And then, spleen cells were seperated from each mouse after 4 weeks. Cytokine measurement in the spleen spleen cells (2 $\times 10^{6} / \mathrm{mL}$ ) were cultured for $48 \mathrm{hrs}$ in the culture dish (Corning Inc, USA.), which had been coated with CD3 mAb of $0.5 \mu \mathrm{g} / \mathrm{mL}$ in $12 \mathrm{hrs}$ before. Then, IL-4 and IL-13 were determined by using ELISA kit. Then the plate was washed twice, and $100 \mu \mathrm{L}$ of AvidinHRP conjugated antibody was treated, washed, and TMB solution was treated for $30 \mathrm{~min}$ in the dark. After stopping the reaction with $50 \mu \mathrm{L}$ of stop solution, the absorbance at $450 \mathrm{~nm}$ was measured by using ELISA reader.

\section{Histological Analysis}

Histological evaluation was performed on lungs. Lungs were inflated with PBS containing heparin, tied off, and removed from the mice and placed in $10 \%$ formalin. After 10 days in formalin, 
the lungs were initially assessed macroscopically for affected percentage, and then embedded into paraffin, sectioned at $5 \mu \mathrm{m}$ thickness, and stained with hematoxylin and eosin as described before [17]. Histological analysis was carried out under a light microscope (Leica DM 1000, Germany) at high magnification (250×). All macroscopic and microscopic lesions were analyzed independently by a resperatory experter blinded from the study.

\section{Statistical Analysis}

Results are expressed as means \pm standard deviation. The data were analyzed using ANOVA and Duncan's multiple range tests. Significance was indicated at a $\mathrm{p}<0.05,<0.01$, and $<0.001$.

\section{Result}

\section{Q3G7R Reduce OVA-Specific IgE in Serum}

Six-week-old Balb/c male injected intraperitoneally with Q3G7R for $0,7,14,21$ and 28 days. OVA-CT group increased

(A)

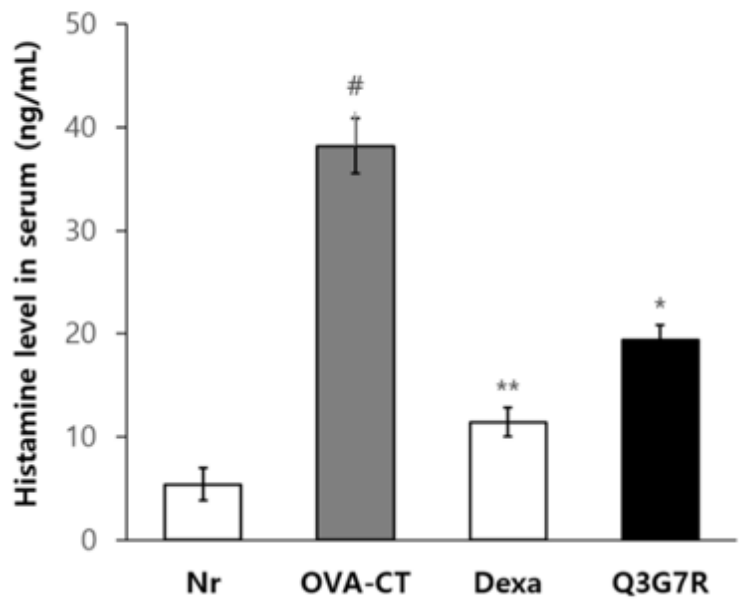

significantly IgE as compared to the $\mathrm{Nr}$ group ( $\mathrm{p}>0.05$; Figure 2 ). The positive control group, Dexa, was to suppress the generation of IgE significantly at 4 weeks ( $p>0.001$; (Figure 2)). Q3G7R showed a significant reduction of IgE in 4 weeks ( $p>0.01$; (Figure 2)).

\section{Q3G7R Decrease Histamine and Tryptase Level in Serum}

Serum histamine levels were significantly higher in the OVA-CT group compared with the $\mathrm{Nr}$ group $(\mathrm{p}<0.05)$ and were significantly smaller in the Dexa group ( $\mathrm{p}<0.01 ; 2 \mathrm{mg} / \mathrm{kg})$, and Q3G7R $(200 \mathrm{mg} /$ $\mathrm{kg}$ ) group compared with the OVA-CT group ( $<<0.05$; (Figure $3 \mathrm{~A})$ ). This finding indicated that Q3G7R treatment significantly improved the serum histamine contents in mice with significant difference from the control groups. Serum tryptase levels were significantly increased in the OVA-CT group $(\mathrm{p}<0.05)$. Administration of dexameason $(2 \mathrm{mg} / \mathrm{kg})$ showed significantly lower in the OVACT group ( $<<0.01$; (Figure 3B)). Q3G7R (200 mg/kg) groups significantly decreased the tryptase level of mice serum $(p<0.05)$.

\section{(B)}

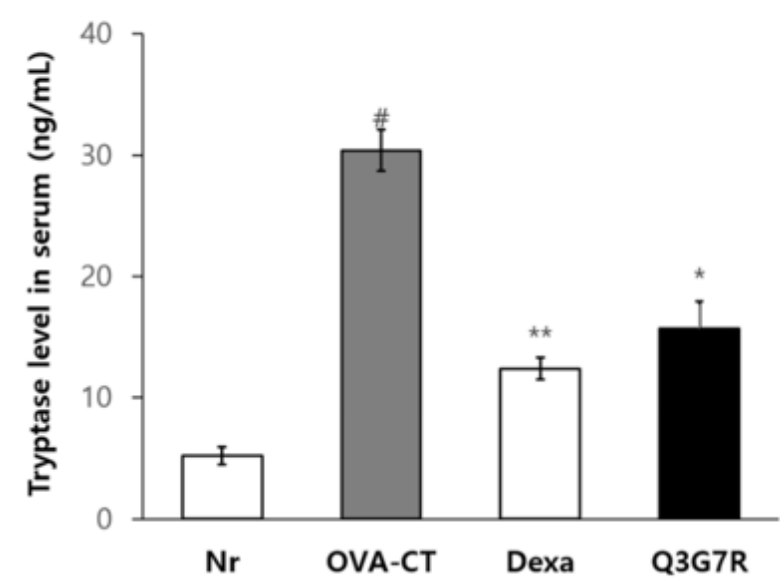

Figure 3: Effect of Q3G7R on the histamine (a) and tryptase levels (b) in ovalbumin applied Balb/c mice. Six-week-old Balb/c male was used, and ovalbumin was injected in intraperitoneally of them for $0,7,14,21$ and 28 days to Balb/c ( $=5$ ). The Q3G7R containing $100 \mathrm{mg}$ of Q3G7R/ $\mathrm{kg}$ body weight per day, dissolved in $0.4 \%$ polyethylene glycol in $0.5 \% \mathrm{EtOH}$, were applied topically, on a daily basis, for 4 weeks. Histamine and tryptase levels in the serum were determined by ELISA kit. $\mathrm{Nr}$, normal; OVA-CT, ovalbumin control; Dexa., dexameason; Q3G7R, 3-O-glucoside-7-O-rhamnoside. \#Significantly different from normal group $(\mathrm{p}>0.05)$. *Significantly different from OVA-CT groups $(\mathrm{p}>0.05)$. ${ }^{*}$ Significantly different from OVA-CT groups $(\mathrm{p}>0.01)$.

\section{Q3G7R Reduce $\mathrm{T}_{\mathrm{h}} 2$ Cells-Derived Cytokines IL-4 and IL-} 13

Ovalbumin was to be intraperitoneal injection. Spleen cells were separated from each mouse after 4 weeks in the 4 groups and was divided on 96 well plate which CD3 mAb was coated at a concentration of $0.5 \mu \mathrm{g} / \mathrm{mL}$ in $12 \mathrm{hrs}$ before. Production of IL-4 and IL-13 was measured with ELISA in the culture supernatant after $48 \mathrm{hrs}$. As a results, $\mathrm{T}_{\mathrm{h}} 2$ cells-derived cytokines IL- 4 and IL13 significantly increased ovalbumin injection $(\mathrm{p}<0.05$; (Figure $4 \mathrm{~A}$ \& 4B)). Dexa treatment significantly reduced increased $\mathrm{T}_{\mathrm{h}} 2$ cellsderived cytokines IL- 4 and IL-13 ( $p>0.01$ and p $>0.001$, respectively, Figure 4A \& 4B). Q3G7R also showed a significant reducing effect of $\mathrm{T}_{\mathrm{h}} 2$ cells-derived cytokines IL- 4 and IL-13 compared to the OVA-CT group ( $(p>0.001$ and $p>0.01$, respectively, (Figure 4A \& 4B)). 
(A)

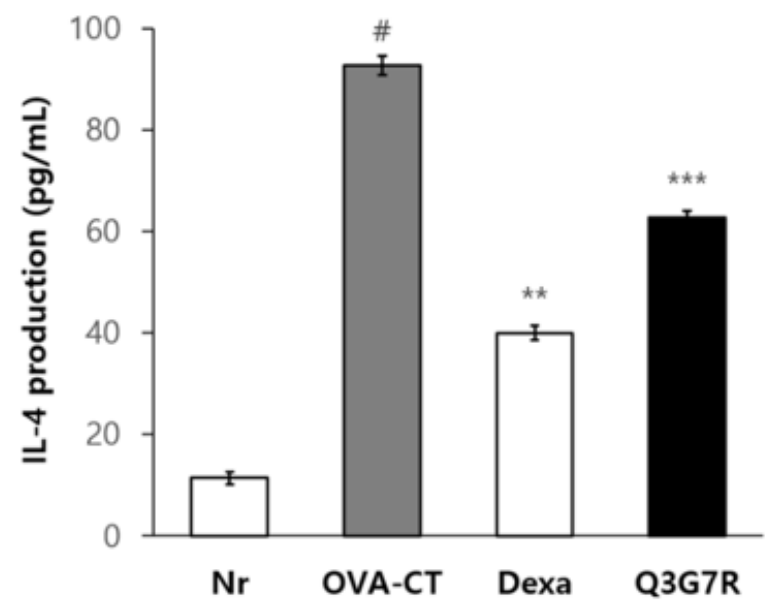

(B)

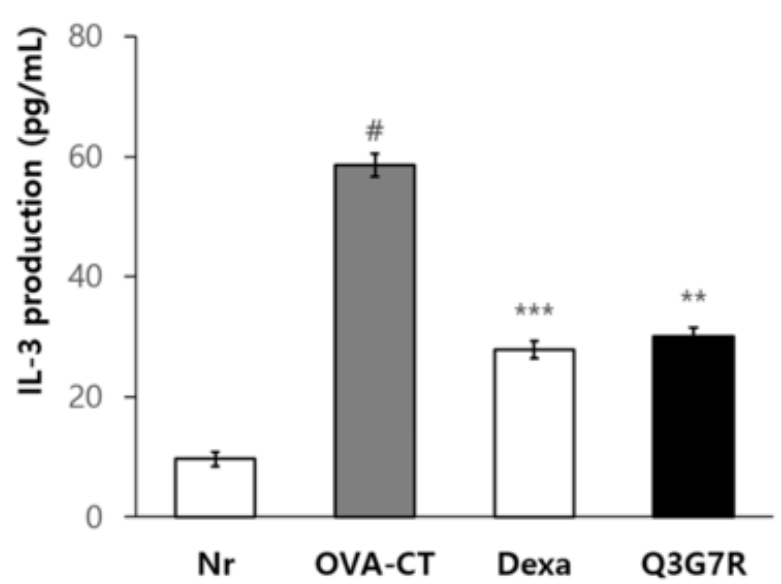

Figure 4: Effect of Q3G7R on IL-4 (a) and IL-13 (b) production in the culture supernatant of CD3 stimulated splenocytes. Balb/c male (6-week-old) was used and ovalbumin was injected in intraperitoneally of them for 0, 7, 14, 21 and 28 days to Balb/c $(\mathrm{n}=5)$. The Q3G7R containing $100 \mathrm{mg}$ of Q3G7R/ $\mathrm{kg}$ body weight per day, dissolved in $0.4 \%$ polyethylene glycol in $0.5 \% \mathrm{EtOH}$, were applied topically, on a daily basis, for 4 weeks. Cytokine measurement in the spleen cells $(2 \times 106 / \mathrm{mL})$ were cultured for $48 \mathrm{~h}$ in the culture dish, which had been coated with CD3 mAb. Then, IL-4 and IL-13 levels were determined by using ELISA kit. Nr, normal; OVA-CT, ovalbumin control; Dexa., dexameason; Q3G7R, 3-O-glucoside-7-O-rhamnoside. \#Significantly

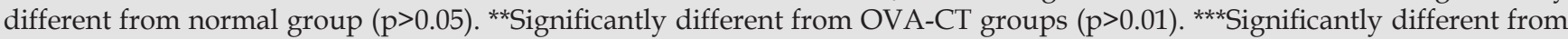
OVA-CTgroups $(\mathrm{p}>0.001)$.

\section{Inhibitory Effect of Characteristic Lesions and Inflammation by Q3G7R}

Histologic analyses were performed of lung samples from mice in 4 weeks. Figure 5 shows representative $\mathrm{H}$ \& E staining of lungs in the $\mathrm{Nr}$, OVA-CT, Dexa (2mg/kg), and Q3G7R (200 mg/kg) groups. The OVA-CT group showed characteristic lesions and inflammation including increased necrosis and numbers of inflammatory cells, and most of infiltrating inflammatory cells in inflammatory sites were eosinophils (Figure 5B). Treatment with Dexa $(2 \mathrm{mg} / \mathrm{kg}$ ) moderately reduced these changes (Figure 5C). Treatment with Q3G7R (200 mg/kg) excellently reduced these characteristic lesions, inflammation and eosinophils (Figure 5D).
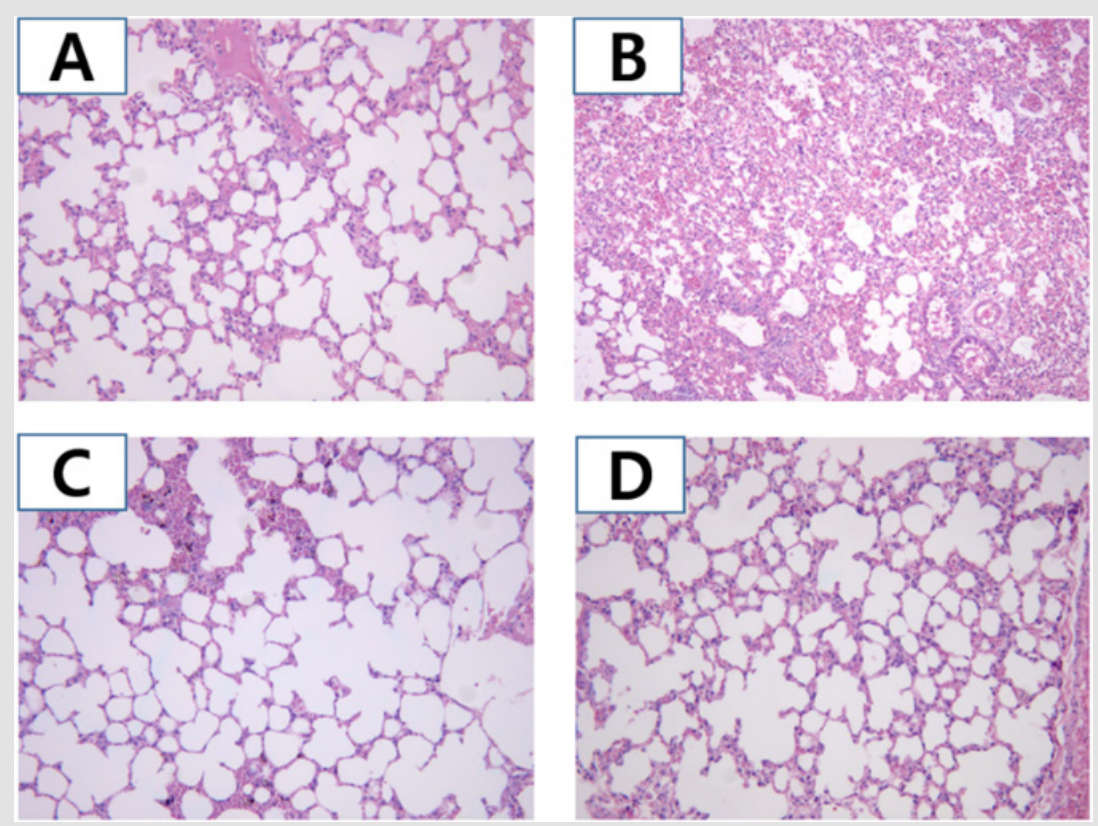

Figure 5: Histological analysis by Q3G7R administration in ovalbumin applied Balb/c mice. Balb/c male (6-week-old) was used and ovalbumin was injected in intraperitoneally of them for $0,7,14,21$ and 28 days to Balb/c ( $n=5)$. The Q3G7R containing $100 \mathrm{mg}$ of Q3G7R/ $\mathrm{kg}$ body weight per day, dissolved in $0.4 \%$ polyethylene glycol in $0.5 \% \mathrm{EtOH}$, were applied topically on a daily basis. After 4 weeks, the lung stained with hematoxylin and eosin and histological analysis was carried out under a light microscope at $250 \times$ magnification. (A), Nr group; (B), OVA-CT group; (C), Dexa group; (D), Q3G7R group. Nr, normal; OVACT, ovalbumin control; Dexa, dexameason; Q3G7R, 3-O-glucoside-7-O-rhamnoside. 


\section{Discussion}

Allergic diseases are a significant health problem today in both developed and developing countries [30]. They have reached epidemic proportions worldwide and their incidence is continuing to increase in association with modern lifestyles [31]. The mechanism underlying the recurrence of allergic diseases is far from resolved [32-34], making it urgent to explore the mechanisms of allergic diseases and to develop new drugs that effectively reduce the rate of recurrence.

To determine whether the Q3G7R can be used to alleviate the allergy-caused inflammatory reactions as an alternative, Q3G7R were used to treat the OVA-induced allergy in a mouse model. Generally, animals demonstrated similar hallmarks to acute human allergy characterized by pathophysiological alterations in airways, mucus secretion, production of allergen specific IgE and the increase of $\mathrm{T}_{\mathrm{h}} 2$ cytokines level [35]. Both clinical and animal experiments have confirmed the production of $\mathrm{T}_{\mathrm{h}} 2$ cytokines in allergy, such as IL-4, IL-5 and IL-13, which can induce the activation of initial effector cells such as eosinophils and mast cells, and subsequently activate many inflammatory mediators, resulting in chronic airway inflammation [36-38]. The results demonstrated that mice treated with Q3G7R significantly reduced OVA-specific IgE, histamine and tryptase levels in the serum of mice compared with OVA-CT group without Q3G7R treatment. Treatment of Q3G7R significantly reduced IL-4 level and increased IL-13 in serum of OVA-challenged mice. In these results, Q3G7R significantly improved the serum histamine contents in mice with significant difference from the OVA-CT group and significantly decreased the tryptase level of mice serum.

The infiltration of lung inflammatory cells (mast cells, lymphocytes and eosinophils), especially those of eosinophils, is representative of inflammatory events of asthma, the severity of which therefore is directly related to the degree of eosinophilia [39]. It has been shown that patients with allergic rhinitis induced by allergen showed an obvious increase in the number of eosinophil peroxidase-stained nasal cavity mucosal eosinophils [40]. Our data showed that treatment with Q3G7R was able to suppress OVAinduced allergic lesions, inflammation and eosinophils in lung. There alleviating effects will be correlated with the regulation of inflammatory cytokines via reduction of OVA-specific IgE, histamine and tryptase levels.

\section{Conclusion}

In conclusion, results in the present study confirmed that Q3G7R possess anti-allergy activities. Further investigation on the mode of action of this Q3G7R will be continued in our future projects.

\section{Conflicts of Interest}

No potential conflicts of interest relevant to this article were reported.

\section{Acknowledgment}

This paper was supported (in part) by Research Funds of Kwangju Women's University in 2019 (KWUI19-049).

\section{References}

1. Larsen JN, Broge L, Jacobi H (2016) Allergy immunotherapy: the future of allergy treatment. Drug Discov Today 21(1): 26-37.

2. Georas SN, Guo J, De Fanis U, Casolaro V (2005) T-helper cell type-2 regulation in allergic disease. Eur Respir J 26(6): 1119-1137.

3. Sicherer SH, Sampson HA (2007) Peanut allergy: emerging concepts and approaches for an apparent epidemic. J Allergy Clin Immuno 120(3): 491-503.

4. Cumming RG, Mitchell P, Leeder SR (1997) Use of inhaled corticosteroids and the risk of cataracts. N Engl J Med Med 337(1): 8-14.

5. Guilbert TW, Morgan WJ, Zeiger RS, Mauger DT, Boehmer SJ, et al. (2006) Long-term inhaled corticosteroids in preschool children at high risk for asthma. N Engl J Med 354(19): 1985-1997.

6. Tan WC (1991) Rational drug strategy in bronchial asthma. Ann Acad Med Singap 20(1): 165-171.

7. Singh NK, Garabadu D, Sharma P, Shrivastava SK, Mishra P (2018) Antiallergy and anti-tussive activity of Clitoria ternatea L. in experimental animals. J Ethnopharmacol 5(224): 15-26.

8. Ghangal R, Raghuvanshi S, Sharma PC (2012) Expressed sequence tagbased identification and expression analysis of some cold inducible elements in seabuckthorn (Hippophae rhamnoides L.). Plant Physiol Biochem 51: 123-128.

9. Arimboor R, Arumughan C (2011) Sea buckthorn (Hippophae rhamnoides) proanthocyanidins inhibit in vitro enzymatic hydrolysis of protein. J Food Sci 76(6): T130-T137.

10. Patel CA, Divakar K, Santani D, Solanki HK, Thakkar JH (2012) Remedial Prospective of Hippophae rhamnoides Linn. (Sea Buckthorn). ISRN Pharmacol 2012: 436857

11. Kruczek M, Swiderski A, Mech-Nowak A, Król K (2012) Antioxidant capacity of crude extracts containing carotenoids from the berries of various cultivars of Sea buckthorn (Hippophae rhamnoides L.). Acta Biochim Pol 59(1): 135-137.

12. Suryakumar G, Gupta A (2011) Medicinal and therapeutic potential of Sea buckthorn (Hippophae rhamnoides L.). J Ethnopharmacol 138(2): 268-278.

13. Suleyman H, Demirezer LO, Buyukokuroglu ME, Gepdiremen A, Banoglu ZN, et al. (2001) Antiulcerogenic effect of Hippophae rhamnoides. Phytotherapy Res 15(1): 625-627.

14. Geetha S, Singh V, Ram MS, Ilavazhagan G, Banerjee PK, et al. (2005) Immunomodulatory effects of seabuckthorn (Hippophae rhamnoides L.) against chromium (VI) induced immunosuppression. Mol Cellular Biochem 278(1-2): 101-109.

15. Geetha S, Sairam M, Sharma SK, Ilavazhagan G, Banerjee PK, Sawhney RC (2009) Cytoprotective and antioxidant activity of Sea buckthorn flavones (Hippophae rhamnoides L.) against tert-butylhydroperoxide induced cytotoxicity in lymphocytes. J Med Food 12(1): 151-158.

16. Goel HC, Prasad J, Singh S, Sagar RK, Kumar IP, et al. (2002) Radioprotection by a herbal preparation of Hippophae rhamnoides RH3 , against whole body lethal irradiation in mice. Phytomedicine 9(1): $15-25$.

17. Xing J, Yang B, Dong Y, Wang B, Wang J, et al. (2002) Effects of sea buckthorn (Hippophae rhamnoides $\mathrm{L}$.) seed and pulp oils on experimental models of gastric ulcer in rats. Fitoterapia 73(7-8): 644-650.

18. Gao ZL, Gu XH, Cheng FT, Jiang FH (2003) Effect of Sea buckthorn on liver fibrosis: a clinical study. World J Gastroenterol 9(7): 1615-1617. 
19. Gupta A, Kumar R, Pal K, Banerjee PK, Sawhney RC (2005) A preclinical study of the effects of Sea buckthorn (Hippophae rhamnoides L.) leaf extract on cutaneous wound healing in albino rats. Inter J Lower Extremity Wounds 4(2): 88-92.

20. Basu M, Prasad R, Jayamurthy P, Pal K, Arumughan C, et al. (2007) Antiatherogenic effects of Sea buckthorn (Hippophae rhamnoides) seed oil. Phytomedicine 14(11): 770-777.

21. Chawla R, Arora R, Singh S, Sagar RK, Sharma RK, et al. (2007) Radioprotective and antioxidant activity of fractionated extracts of berries of Hippophae rhamnoides. J Med Food 10(1): 101-109.

22. Dong TTX, Zhao KJ, Gao QT, Ji ZN, Zhu TT, et al. (2006) Chemical and biological assessment of a Chinese herbal decoction containing radix astragali and radix angelicae sinensis: determination of drug ratio in having optimized properties. J Agric Food Chem 54(7): 2767-2774.

23. Gao QT, Cheung JKH, Li J, Chu GK, Duan R, et al. (2006) A Chinese herbal decoction, danggui buxue tang, prepared from radix astragali and radix angelicae sinensis stimulates the immune responses. Planta Med 72(13):1227-1231.

24. Gao XQ, Ohlander M, Jeppsson N, Björk L, Trajkovski V (2000) Changes in antioxidant effects and their relationship to phytonutrients in fruits of sea buckthorn (Hippophae rhamnoides L.) during maturation. J Agric Food Chem 48(5): 1485-1490.

25. Cheng JY, Kondo K, Suzuki Y, Ikeda Y, Meng X, et al. (2003) Inhibitory effects of total flavonoids of Hippophae rhamnoides L. on thrombosis in mouse femoral artery and in vitro platelet aggregation. Life Sci 72(20): 2263-2271.

26. Geetha S, Ram MS, Singh V, Ilavazhagan G, Sawhney RC (2002) Antioxidant and immunomodulatory properties of sea buckthorn (Hippophae rhamnoides)-an in vitro study. J Ethnopharmacol 79(3): 373-378.

27. Romani A, Pinelli P, Mulinacci N, Vincieri FF, Gravano E, et al. (2000) HPLC analysis of flavonoids and secoiridoids in leaves of Ligustrum vulgare L. (Oleaceae). J Agric Food Chem 48(9): 4091-4096.

28. Siraganian RP (1974) An automated continuous-flow system for the extraction and fluorometric analysis of histamine. Anal Biochem 57(2): 383-394.

ISSN: 2574-1241

DOI: 10.26717/BJSTR.2019.21.003574

Hwa-Jung Choi. Biomed J Sci \& Tech Res

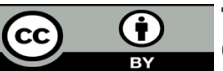

This work is licensed under Creative

Commons Attribution 4.0 License

Submission Link: https://biomedres.us/submit-manuscript.php
29. Granerus G, Lonnqvist B, Nystrand J, Roupe G (1998) Serum tryptase measured with B12 and G5 antibody-based immunoassays in mastocytosis patients and its relation to histamine turnover. $\mathrm{Br} \mathrm{J}$ Dermatol 139(5): 858-861.

30. Larsen JN, Broge L, Jacobi H (2016) Allergy immunotherapy: the future of allergy treatment. Drug Discov Today 21(1): 26-37.

31. Sicherer SH, Sampson HA (2007) Peanut allergy: emerging concepts and approaches for an apparent epidemic. J Allergy Clin Immunol 120(3): 491-503.

32. De Marco R. Locatelli F, Cerveri I, Bugiani M, Marinoni A, et al. (2002) Incidence and remission of asthma: a retrospective study on the natural history of asthma in Italy. J Allergy Clin Immunol 110(2): 228-235.

33. Winer RA, Qin X, Harrington T, Moorman J, Zahran H (2012) Asthma incidence among children and adults: findings from the Behavioral Risk Factor Surveillance system asthma call-back survey-United States, 2006-2008. J asthma 49(1): 16-22.

34. Akerstrom U, Reitamo S, Langeland T, Berg M, Rustad L, et al. (2015) Comparison of moisturizing creams for the prevention of atopic dermatitis relapse: a randomized double-blind controlled multicentre clinical trial. Acta Derm Venereol 95(5): 587-592.

35. Kumar RK, Herbert C, Foster PS (2008) The 'classical' ovalbumin challenge model of asthma in mice. Curr Drug Targets 9(6): 485-494.

36. Mazzarella G, Bianco A, Catena E, De Palma R, Abbate GF (2000) Th1/T 2 lymphocyte polarization in asthma. Allergy 55(Suppl 61): 6-9.

37. Shirai T, Suzuki K, Inui N, Suda T, Chida K, et al. (2003) Th1/T 2 profile in peripheral blood in atopic cough and atopic asthma. Clin Exp Allergy 33(1): 84-89.

38. Tang ML, Coleman J, Kemp AS (1995) Interleukin-4 and interferon- $\gamma$ production in atopic and non-atopic children with asthma. Clin Exp Allergy 25(6): 515-521

39. Sampson AP (2000) The role of eosinophils and neutrophils in inflammation. Clin Exp Allergy 30(Suppl 1): 22-27.

40. Erjefalt JS, Greiff L, Andersson M, Matsson E, Petersen H, et al. (1999) Allergen-induced eosinophil cytolysis is a primary mechanism for granule protein release in human upper airways. Am J Respir Crit Care Med 160(1): 304-312

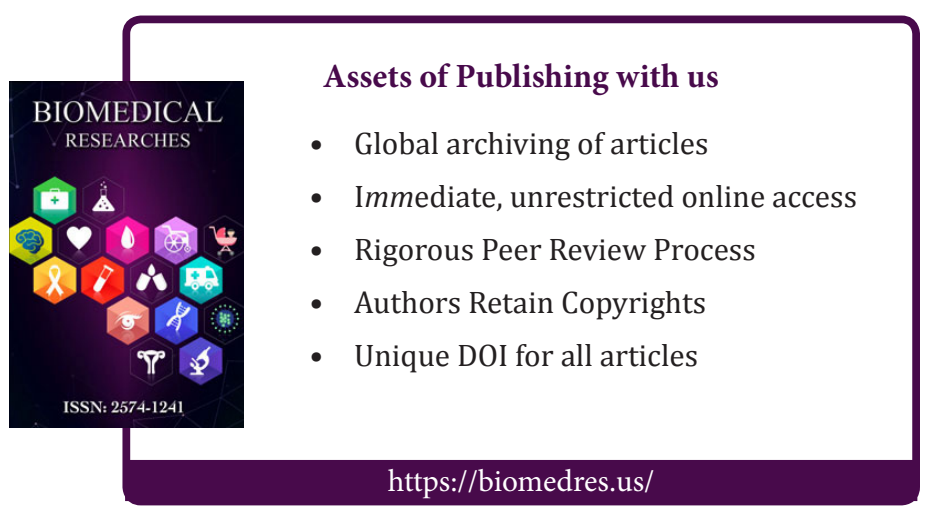

